start in a great new industry. Many will feel that there should be some permanent tribute to the memory of Florey, the mastermind behind the enterprise. He recruited a team from all the necessary disciplines and directed their work with unerring insight and with iron determination. An impoverished university department in the most anxious days of a world war was converted into a factory producing enough penicillin to prove its worth and to enable its properties to be studied fully for the first time. The difficulties which had to be overcome were so formidable that this must rank as the highest achievement of its kind.

\footnotetext{
${ }^{1}$ Fleming, A, British fournal of Experimental Pathology, 1929, 10, 226.

2 Hare, R, The Birth of Penicillin. London, Allen and Unwin, 1970.

${ }^{3}$ Maclean, I H, Rogers, K B, and Fleming, A, Lancet, 1939, 1, 562.
}

\section{Immunosuppression and hepatitis after renal transplantation}

The prevalence of liver disease after renal transplantation varies considerably from unit to unit, ${ }^{1-3}$ though it is by no means rare. Less often recognised is the substantial number of potential recipients who may have some form of chronic liver disease before transplantation. ${ }^{4}$ This is usually an anicteric and subclinical form of chronic persistent hepatitis that may be discovered only by liver biopsy. Among important associated factors is the increased exposure from chronic haemodialysis to the hepatitis $B$ virus and the non- $A$, non- $B$ hepatitis virus, together with the immunodeficiency of chronic uraemia.

While liver disease occurring after transplantation is mostly a mild illness, other, more severe types occur, including fulminant hepatic failure and cirrhosis. Possibilities that have to be considered in the differential diagnosis include an acute viral hepatitis, exacerbation of chronic hepatitis, systemic infection, and azathioprine-related toxicity. Bacterial infections (particularly with Gram-negative organisms such as KlebsiellaEnterobacter and Pseudomonas spp), which so often kill patients taking immunosuppressive drugs after transplantation, ${ }^{5}$ may affect the liver as part of a septicaemia. Whether azathioprine damages the liver in man is uncertain, ${ }^{6-8}$ but it certainly may cause intrahepatic cholestasis. ${ }^{9-11}$ If drug toxicity seems possible then cyclophosphamide can be temporarily substituted. Immunosuppression should not be stopped completely in patients found to be carriers of the hepatitis B surface antigen ( $\mathrm{HBsAg}$ ) (except for very special considerations), for the sudden return of immunocompetence when treatment is stopped may result in massive hepatic necrosis with fulminant liver failure. ${ }^{12}$

Acute or chronic hepatitis accounts for most episodes of liver disease after transplantation. ${ }^{1-3}$ Patients with acute viral hepatitis typically present with jaundice and a febrile constitutional illness. Definitive diagnosis rests on the presence of viral-related antigens, rise in viral antibody titres, and isolation of virus. In many instances the markers of more than one virus are found, often dating from before transplantation and with evidence that the infection has been reactivated after the start of immunosuppression. ${ }^{13-17}$ Cytomegalovirus and hepatitis $B$ virus are the two viruses most often responsible for these infections. Complement-fixing antibodies to cytomegalovirus are commonly found before transplantation,,$^{15-17}$ and their prevalence and titre ${ }^{1617}$ are increased after immunosuppression even in patients without hepatitis. In the absence of other viral markers, when cytomegalovirus is isolated from urine or liver and massive increases in antibody titre are found it can reasonably be assumed to be the cause of an acute hepatitis. ${ }^{3}$

Even if the hepatitis B surface antigen, or the more recently discovered $\mathrm{e}$ antigen (which correlates well with viral replication), is found in the serum of patients with acute hepatitis this does not necessarily mean that the hepatitis $B$ virus is the cause. Outside Britain (and especially in units where $\mathrm{HBsAg}$ carriers are not excluded from transplantation) there may be a high prevalence of these antigens at the time of transplantation. ${ }^{4}$ Now that specific immunoassays for hepatitis A infections have become more widely available these should provide more information on the proportions of cases of post-transplant acute hepatitis due to this virus and to the non-A, non-B virus currently diagnosed by exclusion. Occasionally, acute hepatitis may occur as part of an easily recognisable disseminated viral infection such as herpes simplex. Though the condition often improves spontaneously treatments with interferon, ${ }^{18}$ levamisole, ${ }^{19}$ and adenine arabinoside $^{20}$ are still being evaluated; the last of these seems most worth trying in selected cases.

Persistence of abnormal liver function tests for more than six months usually means the development of either chronic persistent or chronic active hepatitis. Further information about any changes in the liver is essential for management, and a liver biopsy is mandatory. In one series of patients with chronic persistent hepatitis progression to chronic active hepatitis occurred in one-third, all of whom were $\mathrm{HBsAg}$ positive. ${ }^{4} \mathrm{Up}$ to one-half of these patients with chronic active hepatitis may progress to cirrhosis. ${ }^{23}$ Since they are usually already receiving the standard treatment for chronic active hepatitis (azathioprine and corticosteroids) as part of the transplant immunosuppressive regimen there may be few signs clinically. When bleeding from oesophageal varices occurs as a result of portal hypertension then either nonoperative techniques such as endoscopic sclerotherapy of the varices or, if hepatic reserve is good, an end-to-side portosystemic decompression (as recently reported by Dickerman et $\left.a l^{21}\right)$ can be of value.

Interest has grown recently in attempts to forecast the risks of liver disease after transplant on the basis of the various markers of hepatitis B infection before operation. Most studies have found that HBsAg or e antigen is not associated with an increased risk of chronic liver disease, even in the few patients who show the antigen for the first time after transplantation. ${ }^{22-29}$ In contrast, Degos et al ${ }^{4}$ found chronic liver disease and the progression to chronic active hepatitis to be highly correlated with the HBsAg marker. Graft survival was unaffected in most studies ${ }^{23} 28$ or even superior ${ }^{22} 262730$ in these patients; again there was one dissentient, for Pirson and colleagues disagreed. ${ }^{31}{ }^{32}$ If the $\cdot{ }^{\circ}$ is an advantage it may be genetically determined, since $87 \%$ of 38 transplant recipients who were $\mathrm{HBsAg}$ positive before operation possessed an identical antigen (HLA-A2) of a gene locus compared with $54 \%$ in the HBsAg-negative group. ${ }^{30}$

Transplant recipients taking immunosuppressive drugs have an unusual capacity to tolerate (but not eradicate) viral infections. When they show the ability before transplantation to mount an effective humoral immune response to the hepatitis B virus by making anti-HBs antibodies, there is a higher incidence of graft rejection but not of hepatitis. ${ }^{22} 30$ 
Thus, at present, chronic mild viral infection of the liver may be the price paid for better survival of the graft in patients with transplants in whom immunosuppression is effective.

${ }^{1}$ Sopko, J, and Anuras, S, American fournal of Medicine, 1978, 64, 139

2 Anuras, S, et al, Archives of Internal Medicine, 1977, 137, 42.

3 Ware, A J, et al, Gastroenterology, 1975, 68, 755.

${ }^{4}$ Degos, F, et al, Italian fournal of Gastroenterology, 1978, 10, 4.

${ }_{5}^{5}$ Murphy, J F, et al, Archives of Internal Medicine, 1976, 136, 670

${ }^{6}$ Luby, J P, et al, fournal of Infectious Diseases, 1974, 129, 511.

7 Ireland, P, et al, Archives of Internal Medicine, 1973, 132, 29.

${ }^{8}$ Millard, P R, et al, Transplantation, 1973, 16, 527.

9 Sparberg, M, Simon, N, and Del Greco, F, Gastroenterology, 1969, $\mathbf{5 7}, 439$.

10 Zarday, Z, et al, fournal of the American Medical Association, 1972, 222, 690.

11 Berne, T V, et al, Surgery, Gynecology and Obstetrics, 1975, 141, 171.

12 Galbraith, R M, et al, Lancet, 1975, 2, 528.

${ }^{13}$ Fiala, M, et al, fournal of Infectious Diseases, 1975, 132, 421.

14 Nagington, J, Cossart, Y E, and Cohen, B J, Lancet, 1977, 1, 558.

15 Andersen, H K, and Spencer, E S, Acta Medica Scandinavica, 1969, 186, 7 .

${ }^{16}$ Nagington, J, Fournal of Hygiene, 1971, 69, 645

17 Craighead, J E, Hanshaw, J B, and Carpenter, C B, fournal of the American Medical Association, 1967, 201, 725.

18 Greenberg, H B, et al, New England fournal of Medicine, 1976, 295, 517.

19 Pár, A, et al, Lancet, 1977, 1, 702.

${ }^{20}$ Bassendine, M F, et al, Gut, 1978, 19, A991 (abstract).

${ }^{21}$ Dickerman, R M, et al, Surgery, 1978, 84, 322.

22 Rashid, A, et al, Transactions of the American Society for Artificial Internal Organs, 1977, 23, 433.

23 Shons, A R, et al, New England fournal of Medicine, 1977, 296, 1169.

24 Ponticelli, C, et al, New England fournul of Medicine, 1977, 296, 1170.

${ }^{25}$ Rashid, A, et al, New England fournal of Medicine, 1977, 296, 1170.

26 Toussaint, C, New England Fournal of Medicine, 1977, 296, 1171.

27 London, W T, et al, New England Fournal of Medicine, 1977, 296, 241.

${ }^{28}$ Berne, ' T V, Fitzgibbons, T J, and Silberman, H, Transplantation, 1977, 24, 412

29 Fine, R N, et al, Annals of Surgerv, 1977, 185, 411.

30 Opelz, G, and Terasaki, P I, Transplantation, 1978, 25, 159.

31 Pirson, Y, Alexandre, G V P, and de Strihou, C V Y, New England fournal of Medicine, 1977, 296, 194.

32 Pirson, Y, Alexandre, G, and de Strihou, C V Y, New England fournal of Medicine, 1977, 296, 1171.

\section{Digoxin in sinus rhythm}

Since digitalis glycosides were introduced into clinical practice some 200 years ago controversy has continued over the indications for their use. Few physicians would argue with the statement that digoxin is singularly effective for controlling ventricular rate in patients with supraventricular tachyarrhythmias such as atrial fibrillation. Nevertheless, its use as an inotropic agent in patients with heart failure is being questioned with increasing frequency. ${ }^{12}$

Some $20 \%$ of all patients admitted to hospital with a medical (as opposed to surgical) illness are given digoxin. ${ }^{3}$ Toxic effects are seen in some $20 \%$ to $35 \%{ }^{45}$ of these patients. Our increased knowledge about the pharmacokinetics of digoxin together with the use of plasma concentration estimations may improve this figure. Even so, some have doubted the value of plasma digoxin concentrations, ${ }^{6} 7$ particularly for the diagnosis of toxicity, and most of the prescribing aids have proved too complicated for use at the bedside, especially in general practice. ${ }^{89}$ The elderly patient and those patients with impaired renal function remain at the greatest risk of developing digitalis toxicity.

Hence not surprisingly the initial indications for treatment with digoxin have been questioned, particularly in patients with heart failure who are in sinus rhythm. The aim of giving them digitalis is to increase myocardial contractility, but this is only one of the determinants of cardiac performance and preload (venous filling pressure), afterload (peripheral vascular resistance), and heart rate may all require separate attention. ${ }^{10}$ Many doctors think that the widespread use of potent diuretics which will reduce preload by removing salt and water has reduced the need for digoxin. Moreover, vasodilator drugswhich may reduce afterload as well as preload-have been shown to be of value in treating congestive heart failure. ${ }^{11} 12$ This approach, at present more popular in America than in Europe, is likely to be used more frequently and to erode the indications for digitalis even further.

Undoubtedly many patients are taking digoxin unnecessarily as long-term treatment. Furthermore, some $40-50 \%$ of patients for whom digoxin has been prescribed are not taking it properly. ${ }^{1314}$ Several studies have recently reported that digoxin can be withdrawn from the therapeutic regimen of between $75 \%$ and $94 \%$ patients in whom the initial indication for digoxin was congestive heart failure, without ill effect. ${ }^{15-19}$ Most of these patients were in sinus rhythm, and those whose serum digoxin concentration was less than $0.8 \mathrm{ng} / \mathrm{ml}$ (the therapeutic range is $0.8-2.0 \mathrm{ng} / \mathrm{ml}$ ) were least likely to deteriorate when the drug was stopped. Of the 28 patients in sinus rhythm whose plasma digoxin concentration was in the therapeutic range, however, only two developed a recurrence of congestive heart failure when digoxin was stopped. ${ }^{219}$

We have reasonable evidence that, used in the short term, digoxin has an inotropic effect in patients in sinus rhythm with congestive heart failure. ${ }^{20-23}$ Nevertheless, experts still disagree about the long-term use of digoxin in these patients, and whether its inotropic effect persists. The problem has been clarified by two recent studies. McHaffie and his colleagues studied six patients who were taking digoxin and diuretics for congestive heart failure of myocardial origin. ${ }^{19}$ All were in sinus rhythm and had serum concentrations of digoxin in the therapeutic range. After elimination of oedema and achievement of a "dry" basal weight, exercise tests were performed before and at periods after withdrawal of digoxin treatment. No change in symptoms, exercise capacity, respiratory quotient, or sense of well-being was noted when digoxin was stopped. Johnston and McDevitt have also withdrawn digoxin from a group of 22 patients in sinus rhythm in whom the pre-ejection period/left ventricular ejection time ratio was measured as an index of left ventricular function. ${ }^{2}$ In only two of the 17 patients who remained in sinus rhythm was there evidence of reduced left ventricular performance after stopping digoxin, and both patients had clinical heart failure.

Hence in most patients in sinus rhythm digoxin has no long-term stimulatory action on the heart. Nevertheless, the occasional patient will deteriorate clinically: in one study nearly $35 \%$ of 46 patients appeared to relapse on substituting placebo for their digoxin. ${ }^{16}$ In the long term, particularly in the elderly with their increased risks of toxicity, the doctor should consider withdrawing digoxin treatment. If he does he should keep a careful watch for signs and symptoms of deterioration over the next few weeks. Hence a rational recommendation is to give adequate diuretic treatment as the first approach to patients with heart failure who are in sinus rhythm. Digoxin should then be added if the symptoms or signs persist.

${ }^{1}$ Guz, A, and McHaffie, D, Clinical Science and Molecular Medicine, 1978, 55, 417 .

2 Johnston, G D, and McDevitt, D G, Lancet, 1979, 1, 567.

${ }^{3}$ Shapiro, S, et al, fournal of Chronic Diseases, 1969, 22, 361.

${ }^{4}$ Smith, T W, American fournal of Medicine, 1975, 58, 470. 